\title{
FILTERING TECHNIQUES ON ANALYSIS OF ARCHEOLOGY AREAS USING RADARSAT IMAGES: CASE STUDY OF LEMBAH BUJANG, MALAYSIA
}

\author{
M.N. Norzailawati ${ }^{\text {a* }}$, R.S. Akma ${ }^{\text {a }}$, A. Alias ${ }^{\text {a }}$ and Zuraini Md.Ali ${ }^{\text {b }}$ \\ ${ }^{a}$ Urban and Regional Planning Department, Kulliyah Architecture and Environmental Design, \\ International Islamic University of Malaysia, 50728 Kuala Lumpur, Malaysia \\ ${ }^{\mathrm{b}}$ Department of Building Surveying,Faculty of Built Environment, \\ University Malaya of Malaysia,50603 Kuala Lumpur, Malaysia. \\ norzailawati@iium.edu.my
}

Commission VI, WG VI/4

KEY WORDS: Remote Sensing, GIS, Filtering Techniques, Land Use Planning and historical sites

\begin{abstract}
:
Speckle noise present in radar imagery caused by interaction of out -of-phase waves with a target, the objective of this paper is attempt to test filtering techniques consist of Lee, Frost and Gamma Map to identify a potential shrines area in Lembah Bujang using RADARSAT imageries. The multi-temporal images of RADARSAT for years 2003 and 2014 have been used filtering techniques in identifying potential shrines consist of have been used and tested to selected study areas with using processing software of ENVI 4.8 and ArcGIS 10.2. Based on mathematical morphology, the speckles in these images were reduced, once the reduction is achieved, the enhancement of archaeological sites is accomplished. The finding shows that Local Adaptive Filtering on GAMMA Map filter is the best techniques in identifying potential shrines areas at once as guidance to pursuing an area as official gazette historical site in Malaysia context
\end{abstract}

\section{INTRODUCTION}

\subsection{Background of study}

Lembah Bujang was an international cultural and commercial crossroad 2000 years age. Its history, its potential, economic and socio - cultural administrator and significance, its art and architecture, its diplomatic relationship and so on offer fertile ground for scholar investigation. Lembah Bujang, a place located in northern Malaysia (Kuala Muda, Kedah) is one of the most remarkable archaeological sites (Mokhtar, Saidin 2010). Recently, these pre-historic ruins at archaeological sites in Lembah Bujang some 1200 years old were secretly demolished by land developer. Some site has been dug up from its spot with particular shrines hidden from sight believed an old palm and state so the developer probably demolish it first before clearing the oil palm trees. Outraged those ancient and significant archaeological sites were not only unprotected but also allow to be dug up to make way for the development. At present, most of cultural heritage legislation and management is based on expensive and old-fashioned methods of field survey which underpin regional and national registers of cultural heritage sites. This old method had been influenced realistic forecasting and lack of reliable data and causes costly and time consuming due to their application over large areas and introduces unnecessary conflicts.

Since a spectacular series of missions in the context of the Earth Observing System (EOS) by NASA beginning from the late 1990's, the significance of the satellite remote sensing has been recognized all over the world (Kafatos \& Qu, 2007 and
Kaufman et al., 1998). The capability of remote sensing techniques offer the advantage of providing a synoptic view, covering large areas, and demonstrating the capability to detect features not easily visible on the ground that may be important for archaeological applications (Brivio et al., 2000). Nevertheless, the availability of multi- spectral data proved to be an effective data source for paleo-geographic environment studies (Brivio et al., 2000; Parry, 1992). The used of remote sensing techniques in both historic and prehistoric site discrimination is well documented (Lyons, 1977, Lyons and Hitchcock, 1977 and Kruckman, 1972). RADARSAT1 provides horizontal transmit and horizontal receiver $(\mathrm{HH})$ data (793-821 km altitude), RADARSAT2 was launched 2008, provides $\mathrm{VV}$ polarization, cross polarization $(\mathrm{HV}$ or $\mathrm{VH})$, dual polarization ( $\mathrm{HH}+\mathrm{HV} @ \mathrm{VV}+\mathrm{VH})$ and quad-polarization $(\mathrm{HH}+\mathrm{VV}+\mathrm{HV}+\mathrm{VH})$ which makes RADARSAT and incredibly versatile imagery type.

The application of radar to a later phase of development seems to be the most promising in terms of cultural heritage site localization and monitoring, and has already shown its usefulness (Grøn et al. 1999; Holm-Olsen et al. 1999; Shennan \& Donoghue D. 1991). SAR system (synthetic aperture radar) is one of the recent active sensors used for archaeological investigation which can be operated from satellites facilitate registration of small-scale topographical features (penetrating vegetation), variation in ground moisture, and the occurrence of stones. SAR datasets, with the ability to record data beneath the earth`s surface have been applied to a number of archaeological investigations. In the central Iberian Peninsula of Spain, SAR 
data (with a $2.4-13.7 \mathrm{~m}$ resolution) found potentially buried architecture (Ayuga et al, 2006).

SAR data has also been used to detect archaeological site not discovered during foot survey (Sarah, 2009). In examining structural patterns at Petra, Jordan, SAR detected previously unknown linear features. The data also showed ancient pathway, open subterranean chambers, and natural landforms related to known archaeological sites. This study continues at Beidha, Jordan through a cultural sites analysis initiative, which identified the general landscape condition of the area (Comer, 2003). AIRSAR has also been used extensively at Angkor Wat to understand more complicated human-environment interactions (Evan et al, 2007). Other relevant references on work done at an early Bronze Age site in Israel, Leviah Enclosure (not seen in the ground or in aramid photographs) also was detected with ATR and later confirmed with excavation (Ben dor et al, 1989, 2001). Therefore, the objective of this study to identify a potential shrines area in Lembah Bujang using RADARSAT and GIS techniques in conserving the historical site in the context of efficient land use planning.

\section{REMOTE SENSING IN ARCHEOLOGIES}

On another level, satellite images were used to investigate ritual spaces and cultural landscapes (Ray and Ravindranath, 2007). A few attempts were made to detect structural features at sites (Rajani and Settar, 2009; Uday Raj et al., 2005). Early Remote Sensing applications in archaeology started in the 1920s, immediately after the First World War which is an aerial photography was applied for the detection of archaeological sites which were partially or totally buried, or in any case not visible from the ground. This method mostly developed in northern European and systematically used till the 1970s and it's permitting significant discoveries. In the $1940 \mathrm{~s}$ the introduction of infrared films and infrared (false-color) films produced a significant shift in results, permitting even more refined evaluations, by means of traditional analogue photointerpretation technique. The first satellite images used in archaeology were known as CORONA imagery which is in that period more than 800,000 high-resolution photos were taken in the North-East area of the United States.

SAR system (synthetic aperture radar) is one of the recent active sensors used for archaeological investigation which can be operated from satellites facilitate registration of small-scale topographical features (penetrating vegetation), variation in ground moisture, and the occurrence of stones. A synthetic aperture is constructed by moving a real aperture or antenna through a series of positions along the flight track. Synthetic aperture radar is now a mature technique used to generate radar images in which fine detail can be resolved. SAR has various properties that can be exploited for archaeological prospection. Despite this drawback, early application of SAR in archaeology date back to the 1980s and undoubted enabled numerous important discoveries sand provided new insights in vast desert areas, as in the case of Sahara (El-Bazet al .,2007).

The fact that SAR is an active sensor measuring microwave backscatter makes it sensitive to differences in surface roughness which can be seen as variations of brightness and texture in images of $S A R$ backscatter amplitude (Ford et al., 1983; Holcomb and Shingiray, 2007; Cigna et al., 2013; Tapete et al., 2013). SAR backscatter is very much dependent on the dielectric properties of targets, such as soils with a major contributing factor is the soil moisture content (Ulaby et al.,
1982; Holcomb and Shingiray, 2007). This property has been exploited for archaeological prospection in identifying moisture anomalies that indicated the presence of sites of archaeological interest (Moore et al., 2006). Backscatter also has been determined depending on certain conditions; transmission of the microwave field that can take place through a target medium (Ulaby et al., 1982; Morrison, 2013). One condition that affects the depth of penetration is the dielectric constant of the medium (Ulaby et al., 1982). Another condition is wavelength of the microwave field, with longer wavelengths providing further penetration (Ulaby et al., 1982; Schaber, 1999; Schaber and Breed, 1999). The rational of using SAR in archaeology is that shows a different surface and features exhibit different characteristic and therefore on the basis of the given SAR observation parameters, the backscattering coefficient provides information about surface characteristic, such as surface roughness, dielectric properties (moisture) and incidence angle also polarization and environment condition in certain cases .

\subsection{Filtering techniques for RADARSAT}

Remotely sensed optical images from satellite sensors can meet most needs in the practical applications; considerable weatherdependence limits its functional deployment under some circumstances. In practical applications, the optical satellite images, in particular with high resolutions from sensors such as SPOT (Chevrel et al., 1981) and IKONOS (Tanaka \& Sugimura, 2001), provides excellent legibility, but they may be affected by the clouds and weather conditions. On the other hand, SAR images are not influenced by climate and they can be obtained day-and-night, but they suffer from a serious intrinsic speckle or noise (Franceschetti \& Lanari, 1999, Lampropoulos \& Boulter, 1997). In related to this, the joint application of these two different kinds of data information will be great interest for many geological problems that associated with the remote sensing (Chen et al., 2003).

Reducing noise from a satellite imageries are a challenge for the researchers in digital image processing. Generally speckle noise is commonly found in synthetic aperture radar images, satellite images and in the ultrasound medical images. It is a granular noise that inherently exists in and degrades the quality of the Active Radar and Synthetic Aperture Radar (SAR) images. Speckle noise in conventional radar results from random fluctuations in the return signal from an object that is no bigger than a single image processing element. It increases the mean grey level of a local area demonstrate image with speckle noise (Nayan et al 2014). Several approaches are there for noise reduction was filtering. Filtering is a transformation of the pixel intensity values to reveal certain image characteristics such as enhancement of the images means to improves contrast, smoothing which remove noises known as speckles and template matching which detects known patterns by locate the template in the images. The common filters that applied in radar imagery is local adaptive filters including the Lee filter (Lee, 1980, 1981), Frost filter (Frost et al., 1981, 1982), Kuan filter (Kuan et al., 1985), Gamma (MAP or Maximum A Posteriori) filter (Kuan et al., 1987; Lopes et al., 1993), and Lee-sigma filter (Lee, 1983). All of these adaptive filters aim to effectively reduce speckle in radar images without eliminating the fine details (Jensen, 2004).

Local Adaptive Filters, such as the Lee filter are based on the assumption that the mean and variance of the pixel of interest are equal to the local mean and variance of all pixels within the user-selected moving window (Lee, 1980, 1981). It was 
believed that it can reduce speckle/noise while preserving the edges in the images it removes the noise by minimizing either the mean square error or the weighted least square estimation. This filter assumes multiplicative noise and stationary statistic. The Frost filter replaces the pixels of interest with a weighted sum of the values within the moving window (Frost et al., 1981, 1982). The weighting factors decrease with distance from the pixel of interest and increase for the central pixels as variance within the window increases. The principles of frost filters are the un-speckled pixel value estimated using a sub window of the processing window. The size of the sub window varies as a function of the target local heterogeneity measured with the coefficient of variation means that the larger the coefficient of variation (standard deviation) the narrow the processing subwindow. The Gamma (MAP: Maximum A Posteriori) filter was developed by Lopes et al., (1993) based on the improved Kuan MAP filter (Kuan et al., 1987). A priori knowledge of the probability density function of the scene is required before the filter can be applied. It is derived under the assumption of the images scene having a Gamma Distribution, which is believed more suitable to the realistic case. The advantage of this filtering technique is their accuracy in estimating the backscattering coefficient inside homogenous area while preserving the edge and texture of the images non-homogenous scene.

\section{RESEARCH METHODOLOGY}

\subsection{Study Area}

Lembah Bujang is located in Sungai Petani, South Kedah (northern Malaysia), and covered the coastal plain around mount Jerai (1,300 meters high). The mountain is not only landmark but also rich in minerals and was believed to be the sacred home of powerful deity during the period. It is one of the most significant findings of evidences proving the earliest civilizations of Malay Peninsula and become a strategic area for settlement and centre for trade and industry (Jacq-Hergoualc'h, 1992) and lying halfway between the major civilisation of AsiaChina in the east and India and the middle East to the west. Lembah Bujang holds a significant value as a physical prove of the earliest civilization in the Southeast Asia region. The specific study area of Lembah Bujang as follow (Figure 1)

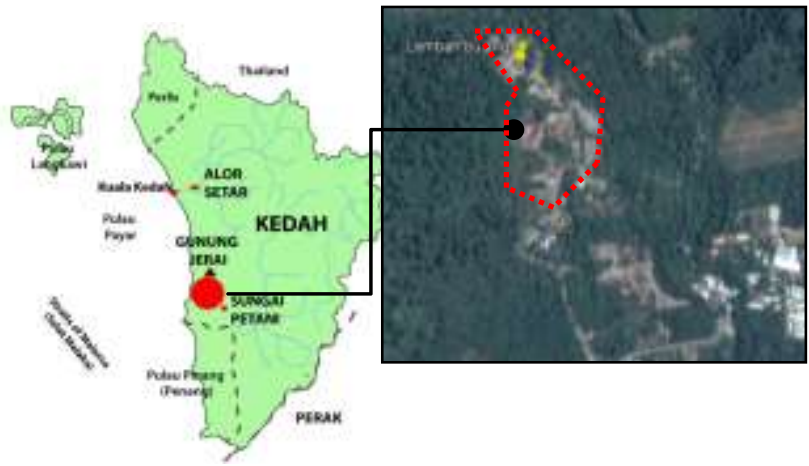

Figure 1: Location map of Lembah Bujang archaeological site.

\subsection{Material and software}

The data has been collected from primary and secondary data sources. The data collected from the primary sources including topographic maps of the area, existing land use map, and imageries used in this study are RADARSAT for multi years of 2003 and 2014. Two SAR datasets, RADARSAT 1 and 2, depicting the same area in the archaeological sites of Lembah Bujang were used to detect potential shrine areas. Table 1 display a detail specification in RADAR imageries used in this study.

Table 1: Detail specification of RADAR imageries used in this study

\begin{tabular}{|l|c|c|}
\hline SPECIFICATIONS & IMAGE 1 & IMAGE 3 \\
\hline Radarsat & RADARSAT1 & RADARSAT2 \\
Acqusition Date & Year 2003 & Year 2014 \\
Modes & Standard & Standard \\
Swath width & Standard & Standard \\
Band & C-Band & C-Band \\
Polarisation & HH & \\
Nominal resolution & Standard: 25m & Standard : 30m \\
\hline
\end{tabular}

\subsection{Methods}

In order to understand the phenomenon of potential shrine locations, the basic requirement is the availability of information of site existing land use categories, topography maps, on site verification and skill of image interpretation. In this study all these required information have been compiled and converted into digital form are readily used in both data processing in Digital Image Processing system and Geographic Information System. The latest ENVI version has been used, while ArcGIS 10.2 software system in GIS used to generate various thematic layers that supporting the main process in detecting potential shrines areas. A complete methodology is shown in figure 2 .

The image pre-processing and data preparation techniques are firstly carried out; these include image rectification and subset. The image- to-map procedures has been applied to the Radar image using set of ground control points area appear in the same place in both images and known locations in corresponding map and urban plan used as ancillary information in the rectification process. The rectified data sets are then subset producing a specific study area in Lembah Bujang which is obtained via ENVI 4.8 .

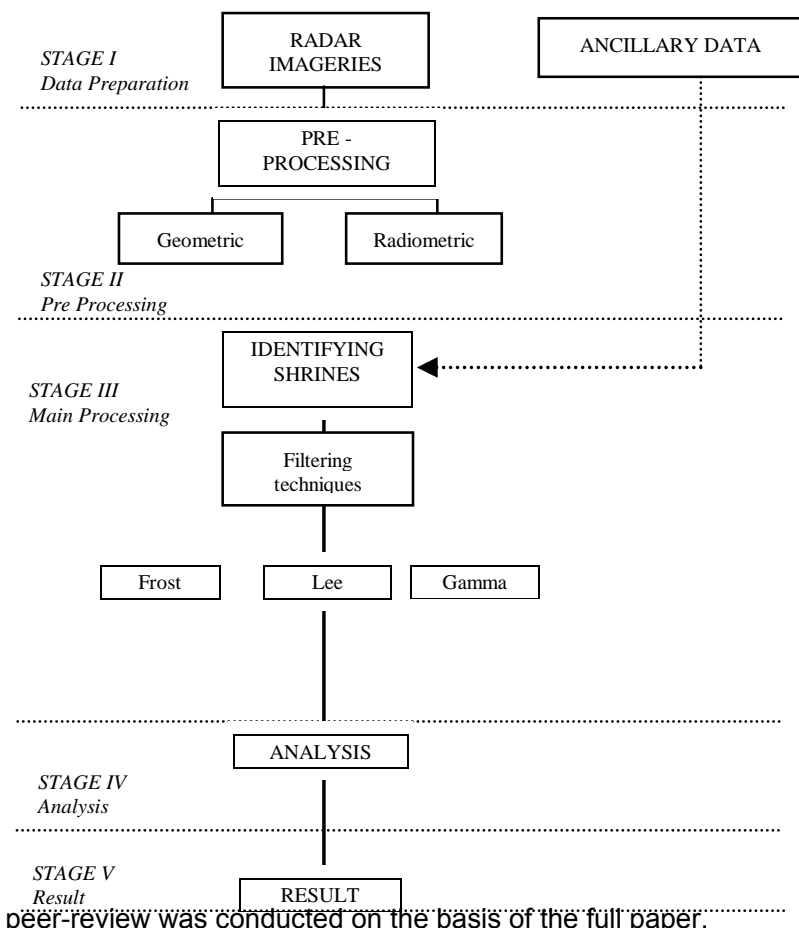



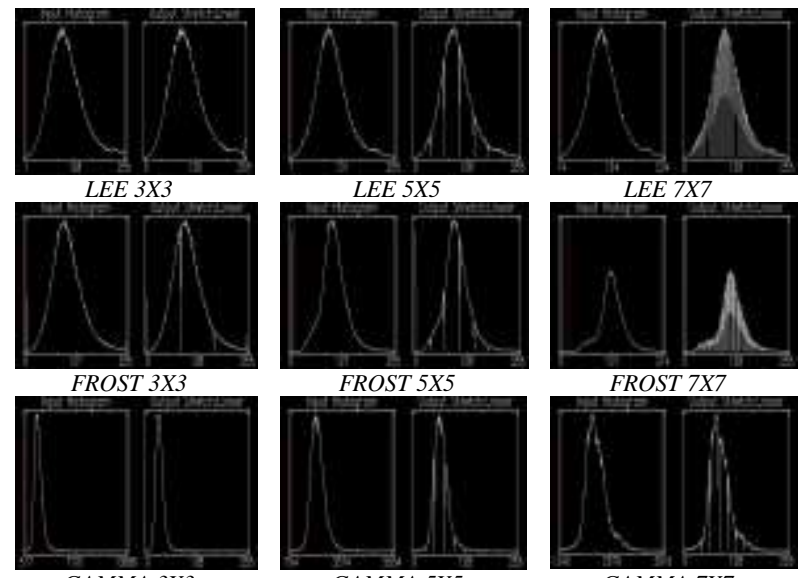

GAMMA $5 X 5$

Figure 2 : Flowchart of data processing adopted in the study

Image filtering is then applied to the pre-processed image, where the map enhancement of the entire study area is produced. The filtering technique had been applied to radar imagery such Lee, Frost and Gamma MAP filter in main processing stage. The advantage of adaptive filtering is their accuracy in estimate the backscattering coefficient inside homogenous (stationary) area while preserving edge and texture structure in non-stationary scenes. The performance of this proposed filter is evaluated and compared the pixel intensity values such as enhancement of the images by using Research System tool; ENVI 4.8 as a method in RADARSAT digital images processing. Various window sizes and six of iterations 3 $\times 3,5 \times 5$ and $7 \times 7$ window sizes are used in order to fully understand the effects imposed by various window sizes and different number of iterations of each filter.

\subsection{Result and Discussion}

The 2 sets of RADARSAT have been successfully geometrically corrected with transformed to local mapping coordinate with RMSE \pm 0.5 pixel to ensure accuracy of shrine analysis. In fact this RMSE had been widely used a good practice in assessing good geometric output apart from ensuring sound configuration of ground control point, evenly distributed in study area. To evaluate proposed filter capability in identifying potential shrine

areas in Lembah Bujang, all the filters available in ENVI have been used using default system parameters, with Lee, Frost and Gamma are applied with user defined multiplier value 1.5 purposely to assess performance of the filters in detailing potential shrine area in study area. The finding shows, Frost filter obscured the linear features and other fine details, resulting in very "fuzzy" filtered images. The result of Lee filter shows better in visual analysis comparing the other filters. (Figure $3 \& 4$ ).

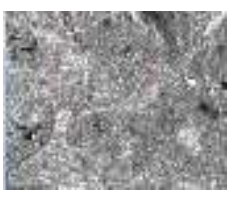

LEE $3 X 3$

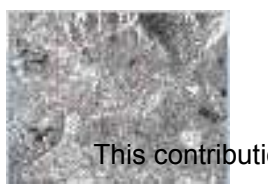

FROST $3 X 3$

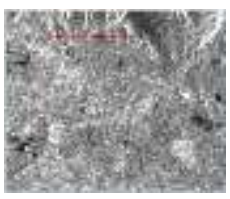

$$
\text { LEE } 5 X 5
$$

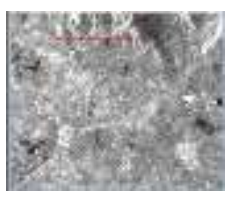

LEE $7 X 7$

Figure 3: Filtering techniques for different windows are tested for Lembah Bujang.

Figure 4: Histogram for different filtering techniques in various window sizes tested for Lembah Bujang area.

This convergent study has provided refinements to the problemsolving process part of the detection of shrine area by using geospatial application technique in the heritage site. The increasing values of the window concomitant the brightness value of the images. Further studies in other filtering techniques can improves the radar images in minimize the speckle texture. It could be useful for those cultural environments in which ground truth or a survey in situ are not available and having constraint in access. SAR data give us the possibility to derive all the information concerning the identified target and detecting underground targets especially a historical area such Lembah Bujang.

\subsection{Conclusion}

The goal of our research is to demonstrate the multi techniques of image processing in attempt to identify potential shrine areas in heritage sites at Lembah Bujang at once to improve the existing tool of urban planning in preserving the historical sites. The used of radar images in this study shows a good significant as a support system and very competent to acquire a better understanding in identifying a potential shrines areas. The future studies suggested here will provide a means for that land use planning development by using the remote sensing technology in the significant site area especially on historical site.

\section{ACKNOWLEDGEMENTS}

The authors greatly acknowledged Universiti Malaya and International Islamic University of Malaysia for Joint research grant on Program Rakan Penyelidikan, Malaysia Remote Sensing Agency (ARSN) and Town and Country Planning Department (JBPD), Centre for Global Archaeological Research (CGAR), Universiti Sains Malaysia, Department of National Heritage and Universiti Teknologi Malaysia for providing invaluable respective data used in this study. Authors sincerely thank all referees for their suggestions to improve the manuscript.

\section{REFERENCES}

Ayuga, J.G.R., Mozota, F.B., Lopez, R. and Abadia, M.F. (2006) "Application of Hyperspectral Remote Sensing To The Celtiberian City Of Segeda," in S. Campana and M. Forte (eds) From Space to Place: 2nd International Conference on Remote Sensing in Archaeology ', Oxford: British Archaeology 
Ben-Dor, Eyal, and Hadas Saaroni (1997) "Video Thermal Radiometry as a tool for monitoring urban heat island. A case study over Tel AvivIsrael, "International Journal of Remote Sensing 18: 3039-3053.

Brivio, P. A., M.Pepe, and R. Tomasoni (2000), Multispectral And Multi- Scale Remote Sensing Data For Archaeological Prospecting In An Alpine Alluvial Plain, J. Cult. Heritage, 1, $155-164$

Chevrel et al., 1981; M. Chevrel, M. Courtois, G. Weill. The SPOT Satellite Remote Sensing Mission. Photogramm. Eng. Remote Sensing, 47 (1981), pp.

Comer D.C. (2003) - Environmental history at an early pre historic village: an application of cultural site analysis at Beidha, in southern Jordan. J. of GIS in Archaeology, 1, 103115

Evans, D., Pottier, C., Fletcher, R., Hensley, S., Tapley, I., Milne, A., Barbetti, M., (2007). A comprehensive archaeological map of the world's largest pre-industrial settlement complex at Angkor, Cambodia. Proceedings of the National Academy of Sciences of the United States of America 104 (36), 14277-14282

Ford, J.P., Cimino, J.B., Elachi, C., (1983). Space Shuttle Columbia Views The World With Imaging Radar: The SIR-A Experiment. JPL Publications, pp. 82-95

Franceschetti, G. \& Lanari, R. (1999). Synthetic Aperture Radar Processing, CRC, 0-8493-7899-0, Boca Raton, FL, USA

Frost, V. S., Stiles, J. A., Shanmugan, K. S., and J. C. Holtzman, 1982, "A Model for Radar Images and Its Application to Adaptive Digital Filtering of Multiplicative Noise," IEEE Transactions on Pattern Analysis and Machine Intelligence,4(2):157-166.

Frost, V. S., Stiles, J. A., Shanmugan, K. S., Holtzman, J. C., and S. A. Smith, (1981), "An Adaptive Filter for Smoothing Noisy Radar Images," in Proceedings of the IEEE, January 1981), 133-155.

Holcomb, D.W., Shingiray, I.L., (2007). Imaging Radar In Archaeological Investigations: An Image Processing Perspective. In: Wiseman, J., El-Baz, F. (Eds.), Remote Sensing in Archaeology. Springer, pp. 11-45

Jacq-Hergoualc'h (1992); Bellwood 1997:262. Once Again, The Bukit Choras Inscription Is A Buddhist Religious Formula In Sanskrit.

Jensen, J.R.,(2004), Introductory Digital Image Processing - a Remote Sensing Perspective, Upper Saddle River, NJ: Prentice Hall, 3rd Ed., 526 p.

Kafatos, M. \& Qu, J.J. (2007). Introduction to science and instruments, In: Earth science satellite remote sensing: Science and instruments, Qu, J.J.; Gao, W.; Kafatos, M.; Murphy, R.E. \& Salomonson, V.V., (Eds.), page numbers (1-11), Tsinghua University Press and Springer, 7-302-12844-8, Beijing and Berlin
Kaufman, Y.J.; Herring, D.D.; Ranson, K.J. \& Collatz, G.J. (1998). Earth Observing System AM1 Mission To Earth. IEEE Transactions on Geosciences and Remote Sensing, Vol.36, No.4, (July 1998) page numbers (1045-1055), 0196-2892

Kruckman, Laurence.(1972). The Techniques and Application of Aeril Photography to Anthropology; A Bibliography. Coun. Planning Librarians Exch. Biblio. \#339. Monticello, 111.

Kuan, D. T., Sawchuk, A. A., Strand, T. C., and P. Chavel, (1985), "Adaptive Noise Smoothing Filter for Image with Signal-Dependent Noise," IEEE Transactions on Pattern Analysis and Machine Intelligence, 7(2):165-177.

Kuan, D. T., Sawchuk, A. A., Strand, T. C., and P. Chavel, (1987), "Adaptive Restoration of Images with Speckle," IEEE Transactions on Acoustics, Speech, and Signal Processing, 35(3):373-383

Lampropoulos, G.A. \& Boulter, J.F. (1997). A New Nonlinear Speckle And Noise Reduction Algorithm, Proceedings of 5th Conference on Infrared Space borne Remote Sensing, pp. 260270, 0-8194-2544-3, San Diego, CA, USA, July 30-August 01, 1997, SPIE, Bellingham, WA, USA

Lee, J.-S., (1980), "Digital Image Enhancement and Noise Filtering by Use of Local Statistics," IEEE Transactions on Pattern Analysis and Machine Intelligence, 2(2):165-168.

Lee, J.-S., (1981), "Speckle Analysis and Smoothing of Synthetic Aperture Radar Images," Computer Graphics and Image Processing, 17(1):24-32

Lee, J.-S., (1983), “A Simple Speckle Smoothing Algorithm for Synthetic Aperture Radar Images," IEEE Transactions on Systems, Man, and Cybernetics, 13(1):85-89

Lopes, A., Nezry, E., Touzi, R., and H. Laur, 1993, "Structure Detection and Statistical Adaptive Speckle Filtering in SAR Images," International Journal of Remote Sensing , 14(9):1735-1758

Lyons, Thomas R and Hitchcock, Robert K (Eds), (1977), Reports of the Chaco Center, No 2, Aerial Remote Sensing Techniques in Archaeology. U S Dept Inter, Nat'l Park Servme, Cult Res Mgt Dew, Washington, D C

Mokhtar Saidin, J. A. (2010). Issues And Problem Of Previous Studies In The Lembah Bujang And The Discovery Of Sungai Batu. Lembah Bujang And Early Civilisation In Southeast Asia , 1-26.

Moore, J. K., and S. C. Doney (2006), Remote Sensing Observations Of Ocean Physical And Biological Properties In The 28 Region Of The Southern Ocean Iron Experiment (Sofex),J. Geophys. $\quad$ Res.,111, xxxxxx, Doi:10.1029/2005JC003289.

Morrison, K., (2013). Mapping Subsurface Archaeology With SAR. Archaeological Prospection 20, 149-160

Nayan, P., Abishek, S and Kruti, D, (2014). A study of Digital Image Filtering Techniques in Spatial Image Processing. Introduction Conference on Convergence of Technology. 9781-4799-3759-2/14 
Parry, J. T. (1992), The investigative role of Landsat TM in the examination of pre-proto-historic water management sites in northeast Thailand, Geocarto Int., 4, 5-24.

Rajani, M.B., Settar, S., 17-21 August (2009). Application of Multispectral Remote Sensing Imagery In Detection of Enclosure Walls of Ancient Walls of Ancient Settlement In South India. In Abstract of Conference on Space Time and Place.III international Conferences on Remote Sensing in Archaeology, Tir-uchirapalli, India

Ray, H.P., Ravindranath, S., (2007). The Archaeology of Ritual Spaces: Satellite Images and Early Chalukyan Temples. Man and Environment XXXII (1), 89-101

Schaber, G.S., (1999). SAR Studies In The Yuma Desert, Arizona: Sand Penetration, Geology, And The Detection Of Military Ordnance Debris. Remote Sensing of the Environment $67,320-347$.

Schaber, G.S., Breed, C.S., (1999). The Importance Of Sar Wavelength In Penetrating Blow Sand In Northern Arizona. Remote Sensing of the Environment 69, 87104.

Shennan, I., and Donoghue, D. (1991): Remote Sensing in Archaeological Research. Proceedings of the British Academy. Vol.77. 223-232

Tanaka, S. and T. Sugimura (2001). "A New Frontier Of Remote Sensing From Ikonos Images." International Journal of Remote Sensing 22: 1-5.

Tapete, D., Cigna, F., Masini, N., Lasaponara, R., (2013). Prospection And Monitoring Of The Archaeological Heritage Of Nasca, Peru, With ENVISAT ASAR. Archaeological Prospection 20, 133-147.

Uday Raj. K.P.Poonacha and S.Adiga (2005). Ruins of Hampi. From igh Resolution Satelitte Data : A case Study In Remote Sensing And Archaeology. ( Tripathy, A.ed) : 90-98. Sundep Prakashan, Delhi.

Ulaby, F.T., Moore, R.K., Fung, A.K., (1982). Microwave Remote Sensing, vol. II. Addison-Wesley Publishing Co, Reading, Massachusetts. 